Dossiê

\title{
A pandemia e a crise internacional das mobilidades humanas ${ }^{*}$
}

\author{
The Pandemic and the International Crisis of \\ Human Mobility
}

La pandemia y la crisis internacional de las movilidades humanas

\section{Comissão Organizadora}

\section{Menara Guizardi}

ORCID: 0000-0003-2670-9360

Pesquisadora Adjunta do Consejo Nacional de Investigaciones Científicas y Técnicas de Argentina (CONICET), vinculada à Escuela de Altos Estudios Sociales de la Universidad Nacional de San Martín (Argentina), e pesquisadora externa da Universidad de Tarapacá (Chile). E-mail: menaraguizardi@ yahoo.com.br

\section{Maria Cristina Dadalto}

ORCID: 0000-0002-7925-3929

Professora do Departamento de Ciências Sociais e Programa de Pós-graduação em Ciências Sociais e História, Universidade Federal do Espírito Santo (Brasil). E-mail: mcdadalto@gmail.com

\footnotetext{
* As autoras agradecem à Agência Nacional de Pesquisa e Desenvolvimento do Chile (ANIDA, em sua sigla em castelhano) que apoiou o desenvolvimento deste texto, por meio do projeto FONDECYT 1190056: "The Boundaries of Gender Violence: Migrant Women's Experiences in South American Border Territories" (20192023).
} 
As crises multidimensionais desencadeadas pela pandemia do COVID-19 vêm provocando, desde o primeiro trimestre de 2020, grandes transformações sociais em todo o planeta. Enfrentam-se circunstâncias sanitárias que desafiam a forma como, nos últimos quarenta anos, organizou-se a circulação econômica, a geopolítica dos Estados-nação, as mobilidades humanas e as funções que as áreas de fronteira cumprem para a articulação entre todos esses âmbitos.

As respostas emergenciais para as contingências sanitárias empurraram os Estados a decisões extremas, que significam um desafio de gestão (Wells et al., 2020:7405). Governos vinculados a forças políticas ideologicamente muito heterogêneas - desde as mais conservadoras até as mais progressistas - parecem não encontrar respostas fáceis (nem instantâneas) à encruzilhada na qual os diversos países se encontram atualmente. O dilema de governabilidade que enfrentam refere-se à necessidade de promover a imobilidade em um mundo que, desde mediados dos anos 80, organizou-se segundo uma lógica de globalização econômica que preconizava estimular os fluxos de pessoas e mercadorias através das fronteiras nacionais (Brítez, 2020:3).

Contudo, seria um reducionismo conceber a globalização somente a partir dessa faceta circulatória, porque configurou-se tensamente entre os desequilíbrios e solavancos de dois interesses contraditórios - embora simbióticos - dos países centrais do capitalismo. Por um lado, estes países, pertencentes ao que denominamos aqui "Norte Global”, buscavam uma crescente capitalização das suas economias, por meio da abertura "sem fronteiras" de mercados, de uma nova divisão internacional do trabalho e da implementação internacionalizada de regimes de ultra-exploração laboral (Smith, 2016). E, por outro, buscavam também o "fechamento" das suas fronteiras aos imigrantes provenientes da periferia capitalista, do "Sul Global”, que, como definiu Grimson (2021:67), constituem a massa humana que não foi plenamente convidada aos benefícios da "festa da globalização".

A crise sanitária que atravessada pela população, coloca o dedo nessa espécie "ferida globalizatória" (e "civilizatória"), removendo o caráter explosivo que a contradição entre "abrir" e "fechar", entre "mobilidade" e "imobilidade" representa para a polarização NorteSul do planeta. Os Estados se encontram, atualmente, impelidos a questionar, regular, controlar ou impedir os fluxos que atravessam suas fronteiras internacionais; a intervir na circulação de mercadorias, nas migrações e nas dinâmicas de trânsito transfronteiriço. Em vários lugares do mundo, esse processo vem-se vinculando perigosamente ao discurso que criminaliza as migrações e mobilidades humanas, aprofundando as práticas restritivas que, 
como sabemos, recaem predominantemente sobre as pessoas e países da periferia capitalista (Slack; Heymann, 2020:1).

No entanto, seria equivocado assumir que esse processo constitui uma novidade; tratase da hegemonia global de um discurso promovido insistentemente pelos países capitalistas centrais (particularmente pelos Estados Unidos), desde os atentados de Nova York (em setembro de 2001) (Grimson, 2018). Tal hegemonia respalda-se no uso do ódio como "recurso moral" (Noel, 2021:87), impugnando o direito dos migrantes internacionais de chegar aos países do Norte Global ou de pertencer a eles em igualdade de condições (jurídicas, sociais, econômicas, políticas, identitárias) com relação à população autóctone (Bauman, 2016). Vale a pena resgatar aqui a lúcida análise de Gabriel Noel (2021), que explica a renovada energia que o recurso moral ao ódio e ao medo possuem atualmente:

Na verdade, como Mary Douglas (1986) argumentou persuasivamente respaldada
por mais de duas décadas de trabalho etnográfico, o ódio e o medo permitem a
construção e subsequente legitimação de laços morais fortes e praticamente
instantâneos em grupos caracterizados por uma sociabilidade frágil, ameaçada ou
incipiente. Isso se dá pela mobilização de uma identificação coletiva que enuncia um
"nós" rodeado de ameaças contra as quais é necessário mobilizar-se de forma
radical, drástica e inflexível para garantir a autopreservação (Noel, 2011) [...]. Como
John e Jean Comaroff (2003) mostraram, o "dentro" e o "fora" estão tensionados em
um paradoxo insolúvel. Vivemos num mundo no qual os Estados se revelam
incapazes de regular os fluxos daquilo que não deveria entrar em suas fronteiras,
mas o faz; e daquilo que deveria permanecer dentro, mas se afasta. Isto se enquadra
numa "ordem" neoliberal que pede aos Estados, simultaneamente e de forma
contraditória, que se abram e fechem. Diante de uma coexistência tão inatingível -
as reivindicações de autenticidade, pureza e identidade, por um lado; e de conexão,
fluxo e abertura, por outro - os discursos e práticas articulados em torno do ódio e
do medo tornam-se centrais como ferramentas de regulação estatal, paraestatal e
infra estatal da vida coletiva. Isto ocorre principalmente nas regiões de fronteira, que
se tornaram espaços onde esses paradoxos e suas consequências assumem contornos
particularmente claros para governos e populações. Da mesma forma, e pelos
mesmos motivos, os migrantes são vistos como um perigo emblemático não só
ligado ao seu conhecido caráter liminar e ambíguo (Douglas, 2007 [1966]), mas
também porque encarnam esta dupla natureza do regime econômico e social
incentivado e exigido pelo neoliberalismo (Noel, 2021:87-88. Ênfases originais,
tradução própria). Essa "tendência" a criminalizar as migrações, a construir esta fronteira entre "nós" e os "demais" radicalizou-se a partir de 2008, com a crise econômica que afetou fortemente os países do Norte Global, evidenciando as fraturas do modelo neoliberal de gestão de seus Estados. Na América do Sul, os impactos dessa crise começam a ser sentidos mais tarde, em 2013. Em 2015, representantes políticos de vários países da região - como Chile, Argentina, Peru, Colômbia e Brasil - começaram a utilizar esses discursos de ódio contra os(as) imigrantes, mas vinculando-os às retóricas racistas, xenofóbicas e misóginas próprias, 
conectadas com as mitologias e mitomanias nacionais (de média e larga duração histórica) (Canelo et al., 2021, Guizardi et al., 2021).

Tanto para os países centrais como para os periféricos, esses usos discursivos do ódio estão fundamentalmente ancorados na disputa entre os ideais circulatórios econômicos da globalização e a consolidação paulatina de uma mentalidade renacionalizadora e soberanista, que iniciou um novo regime de governança das migrações internacionais. Se os anos 80 e 90 foram denominados pelos autores anglófonos a era das migrações (Castles; Miller, 1993), estar-se-ia vivendo agora uma era das crises migratórias (Guizardi et al., 2021). A enunciação sobre a transição entre estas duas "eras" é parte de uma narrativa "norte cêntrica": produzida pelos países do Norte Global e a partir de perspectivas políticas que ignoram os processos do Sul Global (Guizardi et al., 2021).

Essa narrativa propulsiona a transformação dos imaginários globalmente compartilhados sobre os deslocamentos humanos e as fronteiras. Passa-se de um discurso que celebrava as mobilidades transfronteiriças e transnacionais (de forma absolutamente contraditória, como explicitamos antes), a um que fala delas abertamente como um mal a ser perseguido e erradicado. Diferentes autores aludem a esse conjunto de transformações dizendo que a globalização, tal como era conhecida, chegou ao seu fim (Grimson, 2021) e que se vive, atualmente, a "pós-globalização" (Sanahuja, 2017).

Nesse novo ciclo, o imperativo de "fechar as fronteiras" transformou-se na bandeira principal de líderes de países muito dissimilares entre si, com realidades migratórias radicalmente diferentes, como Estados Unidos, Brasil, Chile e Inglaterra. Esse processo se articula, simultaneamente, como uma "fatiga" das instituições democráticas (Appadurai, 2017).

Como indicam Geiselbergue (2017) e colaboradores, vive-se uma "grande regressão" política. Dado que a democracia oferece travas às novas tendências de exploração de caráter ultraneoliberal, várias elites internacionais começaram a apoiar modelos políticos que esvaziam os procedimentos democráticos, retirando ou minando os mecanismos de participação popular (Appadurai, 2017).

Segundo Brown (2017), a democracia experimenta o ataque do neoliberalismo afirmando a indubitabilidade, por parte dos intelectuais neoliberais e dos políticos, de que os mercados são detentores do saber sobre o mais importante para os indivíduos. Nesse sentido, Brown avalia os muros efetivos impulsionadores que acionam imaginários, especialmente aqueles nostálgicos, do passado histórico coletivo das sociedades, e possibilitam, aos países, excluir determinadas situações, a exemplo, o terrorismo, as armas, as drogas, a imigração, etc. 
Por outro lado, vem-se generalizando o descontentamento dos setores sociais médios e pobres em países de todo o mundo, com a progressiva deterioração das condições de vida. A incapacidade (ou falta de interesse) política de fornecer respostas contundentes a essa insatisfação (o que implicaria atacar o modelo de acumulação neoliberal) foi provocando, nas últimas duas décadas, um sentimento internacionalizado de descrédito político. Esse fator ajudou a legitimar a adesão popular a representantes com discursos que evocam as emoções e as crenças pessoais, incentivando a formação de uma esfera pública internacional, na qual a credibilidade individual é mais importante que qualquer compromisso ou ética coletiva.

A eleição de Trump, nos Estados Unidos, a votação do Brexit no Reino Unido, e de Bolsonaro no Brasil são momentos que ilustram esta nova configuração política. Estes acontecimentos expressam o caráter nacionalista das novas hegemonias e o triunfo do discurso antiglobalização que preconiza, literal e metaforicamente, "construir muros" entre os países e "destruir as pontes" que, ao menos potencialmente, os unem. Além disso, essas hegemonias apoiam o uso cada vez mais violento e intensivo de tecnologias bélicas militares para o controle das fronteiras e mobilidades humanas (Brotherton; Kretsedemas, 2018, Domenech; Pereira, 2017, Grimson; Renoldi, 2019, Sanahuja, 2017). Essa retórica é, no entanto, seletiva: assume como positivas as circulações de capitais e mercadorias dos países do Norte global, ao passo que rejeita a possibilidade de que as mobilidades humanas e mercantis do Sul sejam dotadas de uma liberdade equivalente.

Esses discursos vêm consolidando um antagonismo simbólico entre "os cidadãos de bem" e os(as) imigrantes, representados como uma identidade negativa, não convidada e indesejada. Os(as) migrantes são, então, usados como "bodes expiatórios". São responsabilizados pelo empobrecimento global das condições de vida. No entanto, esse é um problema que excede claramente a sua capacidade de agência (já que eles, e ou elas, constituem tão somente $3,4 \%$ da população mundial) e que se deve, isto sim, às fraturas do modelo neoliberal. Na verdade, os(as) migrantes sofrem com esses problemas tanto ou mais do que as populações dos países que os recebem, porque geralmente estão excluídos(as) de diversos direitos sociais e políticos, que poderiam ajudá-los(as) a aliviar as situações de crise.

$\mathrm{O}$ fechamento das fronteiras, devido à emergência sanitária pandêmica, tensionou esses imaginários ainda mais. Vários países do Norte Global estão "aproveitando" a circunstância para aumentar a violência discricionária que exercem sobre os(as) cidadãos(ãs) do Sul Global. Esse cenário afeta centralmente a população latino-americana, conforme explicam Slack e Heymann (2020), acompanhando em situ os acontecimentos da fronteira entre os Estados Unidos (EUA) e o México, em mediados de 2020: 
O COVID-19 expôs totalmente o perigo e a violência na fronteira EUA-México. A abordagem do governo Trump em relação à imigração continua, com o objetivo geral de acabar com ela e com o asilo para pessoas da América Latina e de outros países [...]. A emergência sanitária pública fortalece a discricionariedade do poder executivo, que já é extrema na fronteira, e dá cobertura retórica ao discurso sobre o medo ao exterior, mesmo que não se aplique nesta situação (Slack; Heymann, 2020:1. Tradução própria).

Contudo, paralelamente, sabemos que o controle da mobilidade é uma medida necessária para deter o avanço do vírus, principalmente nos países da periferia global que não dispõem dos recursos estatais (ou das possibilidades de rápida expansão do sistema público de saúde), usufruídos pelos países centrais do capitalismo (Brítez, 2020). Na América do Sul, o colapso sanitário em Brasil, Peru, Equador e Chile, por exemplo, ilustram esse problema. Em resumo: a pandemia reforçou uma noção generalizada de reconfiguração do sistema migratório global, estabelecendo, com uma velocidade inusitada na história recente da humanidade, uma mudança na governança dos deslocamentos humanos planetários.

Esse novo regime em construção parece reinterpretar e associar as mobilidades e o controle de fronteiras às questões de biossegurança. As migrações internacionais e internas em cada país não serão as mesmas depois dessa crise. A reorganização das mobilidades terá um impacto político e econômico que ainda não logramos vislumbrar por completo. As melhores projeções apontam a uma recessão global que durará pelo menos uma década (Wells et al., 2020). Porém, como se sabe, essas circunstâncias afetam as populações de forma diferenciada, dependendo dos fatores de vulnerabilidade aos quais diferentes pessoas ou grupos estão expostos.

Considerando esses debates, o presente dossiê convida a analisar os impactos da crise sanitária provocada pela pandemia do COVID-19 nos processos migratórios internacionais, intranacionais e nas circulações transfronteiriças. Os quatro artigos aqui reunidos indagam especificamente sobre esses desenlaces nos países da América do Sul, observando as transformações nas práticas sociais, nos padrões psicossociais e nas representações acerca das mobilidades humanas. Abordam, ainda, as articulações entre as migrações e as desigualdades (sociais, econômicas, políticas e identitárias), questionando se o novo regime de controle das migrações, que vemos forjar-se nesta pandemia, será mais restritivo, e sua relação com as políticas sanitárias. Finalmente, também se indaga se algumas das perspectivas que associam as migrações aos direitos humanos (atacadas desde 2015, com giro global a extrema-direita) voltam a ter incidência nos discursos públicos ou se, ao contrário, acentua-se a sua retirada política. A partir desses eixos analíticos, os escritos aproximam as pessoas das formas como as comunidades migrantes estão vivenciando o contexto pandêmico. Ao fazê-lo, abrem a 
oportunidade de imaginar, a partir das ciências sociais, os processos de mobilidade humana num futuro pós-pandêmico.

O primeiro artigo do dossiê se titula $O$ controle migratório nas fronteiras do Brasil durante a pandemia: sinais do autoritarismo à nossa porta, de Elisa Marina Fonseca, Mirna de Lima Medeiros e João Irineu de Resende Miranda. A obra propõe analisar as decisões executivas do governo brasileiro, desde março de 2020, sobre as fronteiras e a migração, apoiando-se nas categorias propostas por Arendt, para pensar os governos burocráticos e autoritários. Realiza-se uma detalhada revisão de portarias interministeriais do poder executivo, de Ações Civis Públicas e de reportagens indagando sobre o caráter ilegal das medidas tomadas pelo governo brasileiro. Esse exercício conduz a conclusões transcendentes, segundo as quais "o fechamento de fronteiras, no Brasil, é um projeto político autoritário de contenção migratória, não do vírus: as portarias interministeriais sob análise representam a utilização da burocracia pelo poder político, para subverter o sistema legal" (Fonseca et al., 2021:11).

O segundo texto, Migraciones y COVID-19: Cuando el discurso securitista amenaza el derecho a la salud, de Carolina Stefoni, Báltica Cabieses e Aline Blukacz, leva os leitores às fronteiras setentrionais de Chile. As autoras mostram as contradições do Estado chileno, que vem mantendo dupla moralidade sobre a situação dos(as) migrantes em território nacional. Por um lado, os discursos governamentais vinham promovendo, nos últimos anos, o acesso à saúde dos(as) migrantes e de suas famílias, amparando-se, para tal, nos acordos e tratados internacionais, com enfoque nos direitos humanos. Por outro lado, também vinham radicalizando uma retórica que criminaliza a migração, fortalecendo medidas de controle fronteiriço de carácter militar, persecutório e violento. A partir de dados qualitativos e quantitativos, analisa-se, especificamente, o impacto que a contradição tem sobre a população venezuelana, que enfrenta situações de vulnerabilidade extrema em contextos chilenos pandêmicos (Stefoni et al., 2021).

Em A gestão pública da Covid-19 nas fronteiras brasileiras. O caso do município de Foz do Iguaçu, Lina Magalhães, Luciana Ronconi e Gláucia de Oliveira Assis conduzem os leitores à Tríplice-fronteira do Paraná: região fronteiriça mais transitada de toda América do Sul. As autoras se centram, especificamente, na gestão pública do município brasileiro de Foz de Iguaçu durante a pandemia da Covid-19, perguntando sobre seus impactos multidimensionais nas práticas de mobilidade de populações que vivem, cotidianamente, a circulação na Ciudad del Este (Paraguay) e Porto Iguazú (Argentina). Com tal finalidade, analisam documentos públicos e notícias jornalísticas do período entre março e julho de 2020. 
Concluem que a pandemia "potencializou as desigualdades sociais históricas", posto que "as políticas públicas locais não têm considerado as particularidades do território de fronteira", vulnerabilizando "ainda mais a população transfronteiriça" (Magalhães et al., 2021: 68).

Finalmente, o quinto texto deste dossiê, Escuta em tempos de pandemia: participação em museus a partir da experiência do Museu da Imigração do Estado de São Paulo, de Thiago Haruo Santos e Guilherme Ramalho, faze uma emocionante síntese do desenvolvimento do projeto "Mobilidade Humana e Coronavírus", implementado pela equipe do Museu da Imigração do Estado de São Paulo, da qual participam. Com sensibilidade, o projeto abriu virtualmente as portas do museu, oferecendo escuta aos migrantes internacionais e pesquisadores(as) que trabalham com o tema, construindo, assim, um mosaico das perspectivas destes(as) atores(as) sociais sobre a transformação das mobilidades em plena pandemia. Nesse processo, participação e transformação adentram a um museu fechado pelos protocolos sanitários, mas plenamente aberto ao registro das experiências sensíveis e das reflexões sociais mais urgentes (Santos; Ramalho, 2021).

Esperamos que esses potentes trabalhos possam iniciar uma reflexão transcendente sobre a reorganização dos regimes migratórios e fronteiriços, que ganhará maior relevância política, na medida que avançamos ao final deste período de restrições pandêmicas. Em tempos de desinformação, ódio e medo, a função das ciências sociais é construir visões humanitárias e embasadas em conhecimento científico que possam respaldar as políticas e ações dos Estados.

\section{Referências}

APPADURAI, Arjun (2017), "Democracy fatigue", in H. Geiselberger (Ed.), The Great Regression. Oxford, Polity, pp. 1-13.

BAUMAN, Zygmunt (2016), Extraños llamando a la puerta. Barcelona, Paidós.

BRÍTEZ, Mirta (2020), La educación ante el avance del COVID-19 en Paraguay. Comparativo con países de la Triple Frontera, Preprint Scielo Humanidades. [Consult. 12-07-2021]. Disponível em https://preprints.scielo.org/index.php/scielo/preprint/view/22/579

BROTHERTON, David; KRETSEDEMAS, Philip (Eds.) (2018), Immigration Policy in the Age of Punishment: Detention, Deportation, and Border Control. Columbia, Columbia University Press.

CANELO, Brenda; GAVAZZO, Natalia; NEJAMKIS, Lucila (2021), "The Back and Forth Between National Security and Human Rights: Migration Policies in Argentina Under the Cambiemos Administration (2015-2019)", in M. Guizardi (Ed.), The Migration Crisis in the American Southern Cone: Hate Speech and Its Social Consequences. New York, Springer, pp. 97-126. 
CASTLES, Stephen; MILLER, Mark (1993), The age of migration: International population movements in the modern world. New York, Palgrave.

COMAROFF, John; COMAROFF, Jean (2003), "Ethnography on an awkward scale. Postcolonial anthropology and the violence of abstraction", Ethnography, v. 4, n. 2, pp. 147-179 [Consult. 1207-2021]. Disponível em https://journals.sagepub.com/doi/10.1177/14661381030042001

DOMENECH, Eduardo; PEREIRA, Andrés (2017), "Estudios migratorios e investigación académica sobre las políticas de migraciones internacionales en Argentina", Íconos, n. 58, pp. 83-108 [Consult. 12-07-2021]. Disponível em https://revistas.flacsoandes.edu.ec/iconos/article/view/2487

DOUGLAS, Mary (1986), Como Piensan las Instituciones. Madrid, Alianza.

DOUGLAS, Mary ([1966] 2007), Pureza y Peligro: Un análisis de los conceptos de Contaminación y Tabú. Buenos Aires, Nueva Visión.

FONSECA, Elisa Marina; DE LIMA MEDEIROS, Mirna; DE RESENDE MIRANDA, João Irineu (2021), "O controle migratório nas fronteiras do Brasil durante a pandemia: sinais do autoritarismo à nossa porta", Simbiótica, v. 8, n. 2, pp. 11-37.

GEISELBERGER, Herinrich (Ed.) (2017), The Great Regression. Oxford, Polity.

GRIMSON, Alejandro (2018), "Social anthropology and transnational studies in Latin America: introduction", Etnográfica, v. 22, n. 1, pp. 99-108 [Consult. 12-07-2021]. Disponível em https://journals.openedition.org/etnografica/5167

GRIMSON, Alejandro (2021), “The Waste of Globalization's Party”, in C. S. Ramírez, S. M. Falcón, J. Poblete, S. C. McKay e F. A. Schaeffer (Comps.), Precarity and Belonging. Ithaca, Rutgers University Press, pp. 67-83.

GRIMSON, Alejandro; RENOLDI, Brígida (2019), "Borderization and Public Security in Argentina", in S. Low e M. Maguire (Eds.), Spaces of Security: Ethnographies of Securityscapes, Surveillance and Control. New York, New York University Press, pp. 78-98.

GUIZARDI, Menara; STEFONI, Carolina; GONZÁLVEZ, Herminia; MARDONES, Pablo (2021), "Transnational Heterogeneities. Migration Configurations in the South American Cone (19702020)", in M. Guizardi (Ed.), The Migration Crisis in the American Southern Cone: Hate Speech and Its Social Consequences. New York, Springer, pp. 21-52.

GOZALO-SALELLAS, Ignasi; BASTIDA, Álvaro G.; MUNIENTE, Héctor (2017), Neoliberalismo. "Estamos diante de um novo capítulo". Entrevista com Wendy Brown, Revista IHU on-line. Disponível em http://www.ihu.unisinos.br/78-noticias/574278-neoliberalismo-estamos-diante-deum-novo-capitulo-entrevista-com-wendy-brown [publicada por Ctxt, 30-11-2017, tradução do Cepat.].

MAGALHÃES, Lina; RONCONI, Luciana; DE OLIVEIRA ASSIS, Gláucia (2021), "A gestão pública da Covid-19 nas fronteiras brasileiras. O caso do município de Foz do Iguaçu", Simbiótica, v. 8, n. 2, pp. 67-91.

NOEL, Gabriel (2011), "Guardianes del Paraíso. Génesis y Genealogía de una Identidad Colectiva en Mar de las Pampas, Provincia de Buenos Aires". Revista del Museo de Antropología, v. 4, pp. 211$226 \quad$ [Consult. 12-07-2021].

Disponível

em https://revistas.unc.edu.ar/index.php/antropologia/article/view/5487 
NOEL, Gabriel (2021), "Hate Speech as a Moral Narrative", in M. Guizardi (Ed.), The Migration Crisis in the American Southern Cone: Hate Speech and Its Social Consequences. New York, Springer, pp. 87-96.

SANAHUJA, J.A. (2017). "Posglobalización y ascenso de la extrema derecha: crisis de hegemonía y riesgos sistémicos", in M. Mesa (Ed.), Seguridad internacional y democracia: guerras, militarización y fronteras. Anuario 2016-2017. Madrid, CEIPAZ, pp. 41-78.

SANTOS, Thiago H.; RAMALHO, Guilherme (2021), "Escuta em tempos de pandemia: participação em museus a partir da experiência do Museu da Imigração do Estado de São Paulo", Simbiótica, v. 8, n. 2, pp. 92-114.

SLACK, Jeremy; HEYMANN, Josiah (2020), "Asylum and Mass Detention at the U.S.- Mexico Border during COVID-19", Journal of Latin American Geography, v. 20, n. 10, pp. 1-6 [Consult. 12-07-2021]. Disponível em https://muse.jhu.edu/article/760917/pdf

SMITH, John (2016), Imperialism in the Twenty-First Century: Globalization, Super-Exploitation, and Capitalism's Final Crisis. New York, New York University Press.

STEFONI, Carolina; CABIESES, Báltica; BLUKACZ, Aline (2021), "Migraciones y COVID-19: Cuando el discurso securitista amenaza el derecho a la salud", Simbiótica, v. 8, n. 2, pp. 38-66.

WELLS, Chad; SAH, Pratha; MOGHADAS, Seyed; PANDEY, Abhishek; SHOUKAT, Affan, WANG; Yahing; WANG, Zheng; MEYERS, Lauren; SINGER, Burton; GALVANI, Alison (2020), "Impact of international travel and border control measures on the global spread of the novel 2019 coronavirus outbreak", Proceedings of the National Academy of Sciences, v. 117, n. 13, pp. 7504-7509 [Consult. 12-07-2021]. Disponível em https://www.pnas.org/content/117/13/7504 